Article

\title{
Investigation of Start-Up Characteristics of Thermosyphons Modified with Different Hydrophilic and Hydrophobic Inner Surfaces
}

\author{
Xiaolong Ma, Zhongchao Zhao *, Pengpeng Jiang, Shan Yang, Shilin Li and Xudong Chen
}

School of Energy and Power, Jiangsu University of Science and Technology, Zhenjiang, Jiangsu 212000, China; marlon@stu.just.edu.cn (X.M.); pengpengjiang@stu.just.edu.cn (P.J.); shanyang33@stu.just.edu.cn (S.Y.); shilinli@stu.just.edu.cn (S.L.); xudongchen@stu.just.edu.cn (X.C.)

* Correspondence: zhongchaozhao@just.edu.cn; Tel.: +86-0511-84493050

Received: 20 December 2019; Accepted: 7 February 2020; Published: 9 February 2020

\begin{abstract}
In this paper, the influence of wettability properties on the start-up characteristics of two-phase closed thermosyphons (TPCTs) is investigated. Chemical coating and etching techniques are performed to prepare the surfaces with different wettabilities that is quantified in the form of the contact angle (CA). The 12 TPCTs are processed including the same CA and a different CA combination on the inner surfaces inside both the evaporator and the condenser sections. For TPCTs with the same wettability properties, the introduction of hydrophilic properties inside the evaporator section not only significantly reduces the start-up time but also decreases the start-up temperature. For example, the start-up time of a TPCT with $\mathrm{CA}=28^{\circ}$ at $40 \mathrm{~W}, 60 \mathrm{~W}$ and $80 \mathrm{~W}$ is $46 \%, 50 \%$ and $55 \%$ shorter than that of a TPCT with a smooth surface and the wall superheat degrees is $55 \%$, $39 \%$ and $28 \%$ lower, respectively. For TPCTs with combined hydrophilic and hydrophobic properties, the start-up time spent on the evaporator section with hydrophilic properties is shorter than that of the hydrophobic evaporator section and the smaller $\mathrm{CA}$ on the condenser section shows better results. The start-up time of a TPCT with $\mathrm{CA}=28^{\circ}$ on the evaporator section and $\mathrm{CA}=105^{\circ}$ on the condenser section has the best start-up process at $40 \mathrm{~W}, 60 \mathrm{~W}$ and $80 \mathrm{~W}$ which is $14 \%, 22 \%$ and $26 \%$ shorter than that of a TPCT with smooth surface. Thus, the hydrophilic and hydrophobic modifications play a significant role in promoting the start-up process of a TPCT.
\end{abstract}

Keywords: Thermosyphon; start-up characteristics; hydrophilic and hydrophobic; contact angle

\section{Introduction}

As a two-phase passive device, the thermosyphon has a wide-range of various industrial applications, for instance, electronic equipment [1], heat-recovery systems [2], solar water heater systems [3] and space applications [4] due to the simple structure, reliability, high efficiency and low cost. The basic concept of heat pipes was first proposed by Gaugler in 1944 [5]. A thermosyphon is a gravity-assisted heat pipe without wicks that depends on phase-change heat transfer in both the evaporator and condenser sections to transfer large amounts of heat with relatively small temperature difference [6] and low thermal resistance [7]. Figure 1 shows the schematic diagram of the cross section and working principle of a two-phase closed thermosyphon (TPCT). A TPCT is composed of evaporator, adiabatic and condenser sections. The operating process begins with a certain volume of working fluid in the evaporator section, which is then heated by a source of heat, such as a heating element or a thermal bath. The heating converts the saturated liquid into vapor that rises to the condenser section. Afterwards, the vapor condenses into liquid, which flows back down to the evaporator section by gravity, in the process transferring heat to the heat sink, such as cold water [8]. 


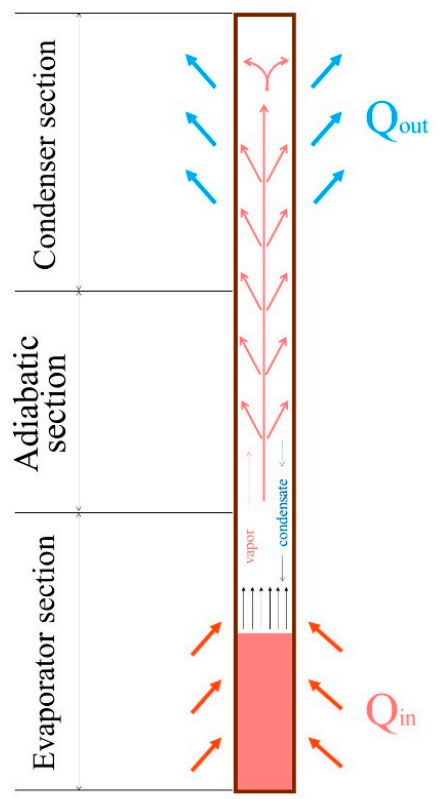

Figure 1. Cross section and working principle of a two-phase closed thermosyphon [9].

At present, the investigation of thermosyphons mainly includes the analysis of the thermal performance and start-up characteristics. In recent years, the thermal performance of thermosyphons in the aspects of filling ratio and surface modifications have been experimentally studied. Lataoui and Jemni [10] conducted an experimental study on a stainless steel thermosyphon to assess the influence of filling ratio, input power and the temperature of the cooling fluid on its thermal performance. Alireza Moradikazerouni et al. [11,12] investigated the effects of surface modifications on the heat sink, and the results found that different structural shapes on the heat surface have various heat transfer mechanisms. Rahimi et al. [13] modified the condenser and evaporator of a thermosyphon and compared the heat performance and resistance of a modified thermosyphon at different input powers with a flat thermosyphon. They found that the average thermal performance at tested heat loads was increased by $15.27 \%$ and the average thermal resistance of the thermosyphon was decreased by 2.35 times. Singh et al. [14] investigated the effect of surface modification on the thermal performance in an evaporator and condenser for flat thermosyphons with and without an anodized surface. Solomon et al. [15] studied the heat performance of thermosyphons with surface modifications at diverse inclination angles and input powers. The surface modifications significantly reduce the wall temperature of the evaporator and increase the heat-transfer coefficient. Solomon et al. [16] also analyzed the thermal performance of an anodized surface with a porous structure and observed a $15 \%$ reduction in the thermal resistance and 15\% increase in the heat-transfer coefficient of the evaporator.

Additionally, Noie [17] investigated the effects of aspect ratio on the thermal performance of a thermosyphon and achieved heat performances of $60 \%, 90 \%$ and $30 \%$ for aspect ratios of $11.8,7.45$ and 9.8, respectively. Gedik [18] reported the influence of various operating conditions, such as heat input, inclination angle and the flow rate of cooling water on the heat-transfer characteristics of a TPCT. Moreover, the method whereby a nanofluid was used as working fluid in a thermosyphon has been theoretically and experimentally studied. Ma et al. [19] found that the heat-transfer rate of a nanofluid can rise to 3.11 times in an inclined square enclosure which indicates that the nanofluid is a potential choice as working fluid. Besides, the nanoadditives of various shapes on the fluid flow and heat transfer aspects of a nanofluid have different influences [20]. Hence, the parameters of surface modifications, operating conditions, working fluid and filling ratio have a great effect on the thermal performance of thermosyphons. Similarly, the start-up performance of the thermosyphon will also be affected by these factors. 
The reliable operation of thermosyphons requires good start-up performance. The start-up of thermosyphon is a complex, transient process that is affected by several parameters. Sun et al. [21] studied the effects of filling ratio and heat input levels on the start-up characteristics of micro-oscillating heat pipes and observed two different start-up behaviors, start-up processes with and without bubble nucleation, depending principally on the spatial distribution of slugs/plugs in the micro-oscillating heat pipes. Guo et al. [22,23] found that the inclination angle is one of the factors that affect the start-up characteristics of thermosyphon. Then the influence of evaporator length on the start-up performance of a sodium-potassium alloy heat pipe was tested and obtained a uniform temperature distribution by increasing the evaporator section length. The Na-K heat pipe had excellent start-up performance, and the increase of inclination angle raised the temperature of the condenser. Wang et al. [24] analyzed the influence of inclination angle, heat input and flow rate of cooling water on the start-up properties of a thermosyphon with small diameter. Huang et al. [25] introduced the non-condensable gas used for regenerative building heating exchangers in a gravity loop thermosyphon and investigated its effect on the start-up time. They found that the non-condensable gas extended the start-up time of the thermosyphon, with a higher level corresponding to a longer time. Joung et al. [26] observed that a large amount of heat leakage increased the operating temperature and the start-up time of a loop heat pipe. In addition, Singh et al. [27] studied the start-up characteristics of a loop heat pipe and found that the start-up time increased with decreasing the applied heat load. Ji et al. [28] designed a loop heat pipe with composite porous wicks, and studied its heat transfer and start-up characteristics. Huang et al. [29] experimentally and mathematically analyzed the start-up process of a loop heat pipe. They concluded that the start-up process was closely subject to the structural parameters and environment of the loop heat pipe.

Although the thermal performance of a thermosyphon has been well studied from different aspects mentioned above, the start-up characteristics of a thermosyphon have been rarely investigated due to its complex and transient process. The start-up characteristics of a thermosyphon is in an unstable state. How to shorten the start-up time and make the thermosyphon quickly reach a stable state has an important impact on the operation of some equipment. Furthermore, the combination of hydrophilic and hydrophobic properties on the inner surfaces of a thermosyphon is barely investigated. As a high-efficiency heat-transfer device, the start-up characteristics of a thermosyphon is an important index to measure the reliability of the thermosyphon, which must be completed quickly and smoothly. Therefore, it is of great significance to investigate the start-up characteristics of a thermosyphon. In this paper, the effect of wettability properties on the start-up characteristics of TPCTs is fully investigated. Chemical coating and etching techniques are employed to manufacture surface wettability with different contact angles (CAs) at the inner wall of the thermosyphon. The influence of the surface with different $\mathrm{CAs}$ on the start-up time and wall superheat degrees of the evaporator section under different input power was compared and analyzed.

\section{Methodology}

\subsection{Experimental System}

Figure 2 shows the schematics of the experimental apparatus, while Figures 3 and 4 show the real thermosyphon and the experimental system, respectively. The experimental system is composed of a thermosyphon, a heat supply unit, a cooling unit and a data acquisition unit. The thermosyphon is made of copper with the lengths of evaporator, adiabatic and condenser sections shown in Figure 2 designed to be $100 \mathrm{~mm}, 50 \mathrm{~mm}$ and $100 \mathrm{~mm}$, and the internal and external diameters of 8.32 and $9.52 \mathrm{~mm}$, respectively. Deionized water of $3.2592 \mathrm{~g}$ is used as the working fluid and the filling ratio was $24 \%$. The heat supply unit included an electrical resistor, a digital power meter and a voltage-regulating transformer. The evaporator and the adiabatic sections are wrapped with a polytetrafluoroethylene nanoparticle insulation in the inner layer and aluminum foil in the outermost layer for the purpose of reducing the heat loss as shown in Figure 4. The cooling system consisted of a refrigerating unit, 
a cooling water jacket, a rotameter of $6 \sim 60 \mathrm{~L} / \mathrm{h}$ and a number of pipelines. The jacket is wrapped with thermal insulation rubber outside. The data acquisition unit is made up of a data logger, a computer and 10 Pt100 thermocouples. The arrangement of 10 thermocouples is shown in Figure 2. In addition, a vacuum pump system consisting of burette, pressure gauge and vacuum pump is used to provide a vacuum in the thermosyphon, and the vacuum degree of each thermosyphon is $10^{-3} \mathrm{~Pa}$. In addition, the boundary conditions of the experiment are shown in Table 1. The 12 TPCTs with different wettability properties on the start-up characteristics are fully investigated under these conditions.

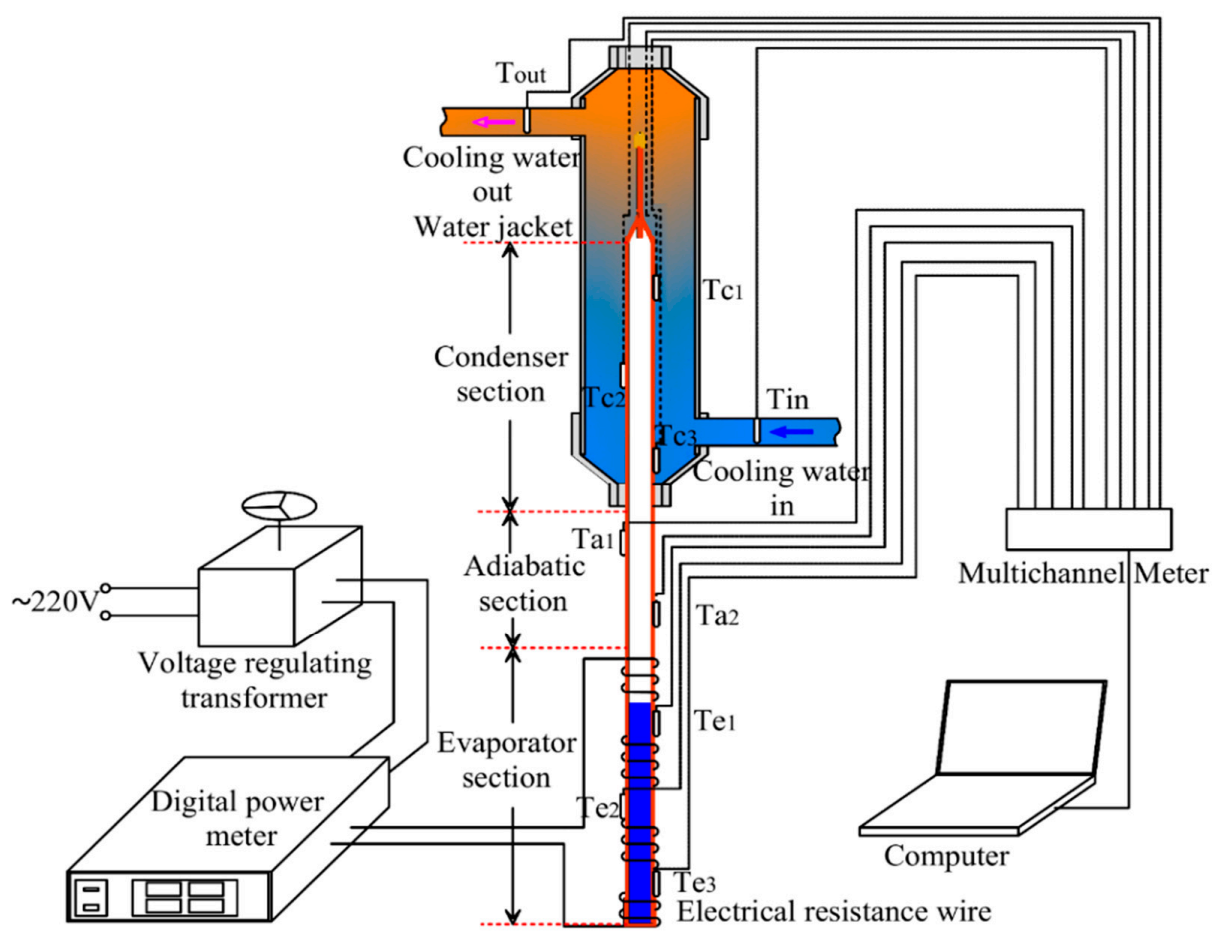

Figure 2. Schematic diagram of experimental apparatus.

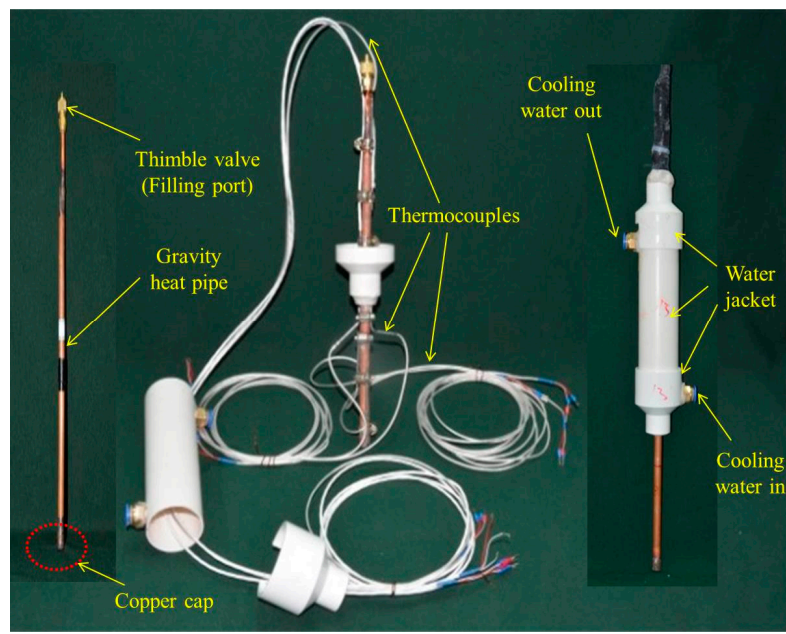

Figure 3. Image of the real thermosyphon used in the experiments.

Table 1. The boundary conditions of the experiment.

\begin{tabular}{ccc}
\hline Input Power $(\mathbf{W})$ & Temperature of Cooling Water $\left({ }^{\circ} \mathbf{C}\right)$ & Flow Rate of Cooling Water $(\mathrm{L} / \mathrm{h})$ \\
\hline 40 & 18 & 20 \\
60 & 18 & 30 \\
80 & 18 & 40 \\
\hline
\end{tabular}




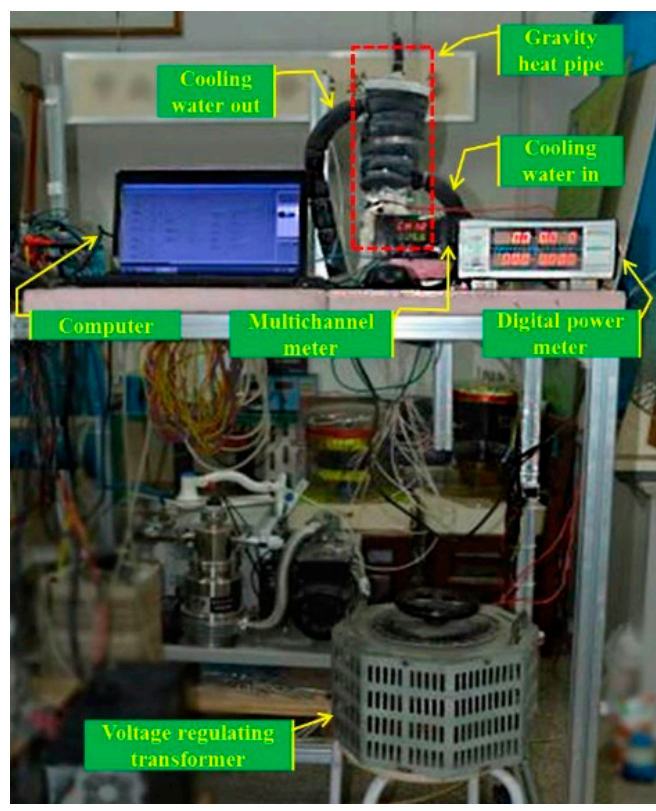

Figure 4. Image of the experimental system.

\subsection{Data Reduction and Problem Description}

The heat transfer between the condenser section and the cooling water under various operating conditions (e.g., working fluid, applied heating power input and mass flow rate of cooling water) is determined using Equation (1):

$$
Q_{c}=m_{w} c_{p}\left(T_{\mathrm{w}, \text { out }}-T_{w, \text { in }}\right)
$$

where $m_{w}$ is the mass flow, $T_{w, i n}$ is the temperature of cooling water at inlet of the condenser, $T_{\mathrm{w}, \text { out }}$ is the temperature at outlet and $c_{p}$ is the specific heat values of water.

During the experiment, strict insulation measures are taken on the outside of the evaporator section, the adiabatic section and the cooling water jacket in order to ensure minimum heat loss. The heat-balance method [9] is used to determine the heat loss of the system. The power relative error is defined as the ratio of the difference between the input heat $Q_{e}$ in the evaporator section and the released heat $Q_{c}$ in the condenser section to the input heat $Q_{e}$, and calculated using Equation (2) as:

$$
\eta=\frac{Q_{e}-Q_{c}}{Q_{e}}
$$

where

$$
Q_{e}=Q_{i n}=V I
$$

$Q_{i n}$ is the heating power input on the evaporator section of the thermosyphon, while $\mathrm{V}$ and I are the voltage and the current monitored by the digital power meter. The measurement error of thermocouples was $\pm 0.5{ }^{\circ} \mathrm{C}$, and the cooling water had a flow rate error of $\pm 2.5 \%$. In the experiment, the maximum power relative error was $7.3 \%$.

The objective of the paper is to investigate the effect of wettability properties on the start-up characteristics of TPCTs. The measurement includes the average start-up time and wall superheat degree of the evaporator section of the thermosyphon under different input power. The main problem in this study is the machining and preparation of different wettability properties on the inner surface. The values of different CAs need distinct process technology $[30,31]$. Besides, the cylindrical shape of the inner wall of the thermosyphon leads to a difficulty of processing and long-term stability. For the preparation of inner wettability surfaces, the techniques are chemical etching, electrochemical deposition, composite coating, anodizing, etc. Chemical coating and etching techniques are used 
to manufacture surface wettability with different CAs at the inner wall of the thermosyphon after a considerable number of experiments.

\subsection{Surface Modification}

In order to prepare the surfaces with various wettabilities in terms of different CAs, chemical techniques are performed using various materials. $\mathrm{NaOH}$ and $\left(\mathrm{NH}_{4}\right)_{2} \mathrm{~S}_{2} \mathrm{O}_{8}$ are used to etch the hydrophilic surface with a CA of approximately $28^{\circ}$. By coating various ratios of materials, such as N-butyl, stearic acid, xylenes and acetone, the CAs of surfaces are approximately $61^{\circ}, 79^{\circ}, 105^{\circ}, 117^{\circ}$ and $142^{\circ}$, respectively. Detailed surface modification methods have been described in the authors' previous work [9].

The 12 thermosyphons correspondingly produced test samples to verify the coating temperature resistance. The coated samples are put on the thermostatic magnetic stirrer for a high-temperature test. The automatic contact angle meter (Kino-SL150E) with the measuring error of $\pm 2^{\circ}$ is used to measure the CA after high-temperature and long-time testing. It is found that the change in the CA is small and the maximum CA error is $4.2 \%$ in the testing temperature from $20^{\circ} \mathrm{C}$ to $100^{\circ} \mathrm{C}$.

In order to ensure the accuracy and reproducibility of the CA of the wet surface, $4 \mu \mathrm{L}$ of deionized water is titrated on each surface 5 times. Finally, the average value of the CA is taken. Figure $5 \mathrm{a}-\mathrm{f}$ show the low- and high-magnification scanning electron microscopy (SEM) images of the surfaces with CAs of $28^{\circ}, 61^{\circ}, 79^{\circ}, 105^{\circ}, 117^{\circ}$ and $142^{\circ}$, respectively, while Figure $5 \mathrm{~g}$ shows the SEM image of a smooth surface. Figure $5 \mathrm{~d}-\mathrm{f}$ demonstrate the hydrophobic surfaces on which $4 \mu \mathrm{L}$ of water is dropped, with the static CAs of $105^{\circ}, 117^{\circ}$ and $142^{\circ}$, respectively, illustrating weak interactions between water drops and hydrophobic surfaces. Water drops are dispersed over the surfaces with the CAs of $28^{\circ}$, $61^{\circ}$ and $79^{\circ}$, subject to high adhesive force between water and coated copper in the evaporator as shown in Figure $5 \mathrm{a}-\mathrm{c}$, respectively. Figure $5 \mathrm{~g}$ shows that the TPCT7 remained smooth, without any resurface work.

According to different wettability properties, the thermosyphons are classified into 12 different TPCTs from TPCT1 to TPCT12 as listed in Table 2. From TPCT1 to TPCT6, each of their three sections has the same CA on the inner surfaces. A combination of hydrophilic and hydrophobic properties with different CAs is adopted to modify the inner surfaces of the evaporator and condenser of TPCTs from TPCT8 to TPCT12, while the inner wall of the three sections of TPCT7 is smooth surface without fabrication.

Table 2. Different two-phase closed thermosyphons (TPCTs) on inner modified surfaces with hydrophilic and hydrophobic properties.

\begin{tabular}{cccc}
\hline TPCTs & Evaporator & Adiabatic & Condenser \\
\hline TPCT1 & $28^{\circ}$ & $28^{\circ}$ & $28^{\circ}$ \\
TPCT2 & $61^{\circ}$ & $61^{\circ}$ & $61^{\circ}$ \\
TPCT3 & $79^{\circ}$ & $79^{\circ}$ & $79^{\circ}$ \\
TPCT4 & $105^{\circ}$ & $105^{\circ}$ & $105^{\circ}$ \\
TPCT5 & $117^{\circ}$ & $117^{\circ}$ & $117^{\circ}$ \\
TPCT6 & $142^{\circ}$ & $142^{\circ}$ & $142^{\circ}$ \\
TPCT7 & smooth surface & smooth surface & smooth surface \\
TPCT8 & $28^{\circ}$ & smooth surface & $105^{\circ}$ \\
TPCT9 & $28^{\circ}$ & smooth surface & $117^{\circ}$ \\
TPCT10 & $28^{\circ}$ & smooth surface & $142^{\circ}$ \\
TPCT11 & $105^{\circ}$ & smooth surface & $28^{\circ}$ \\
TPCT12 & $142^{\circ}$ & smooth surface & $28^{\circ}$ \\
\hline
\end{tabular}




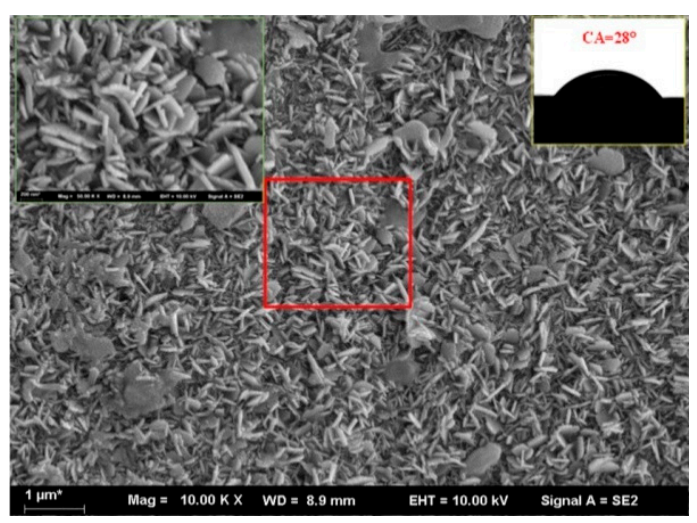

(a)

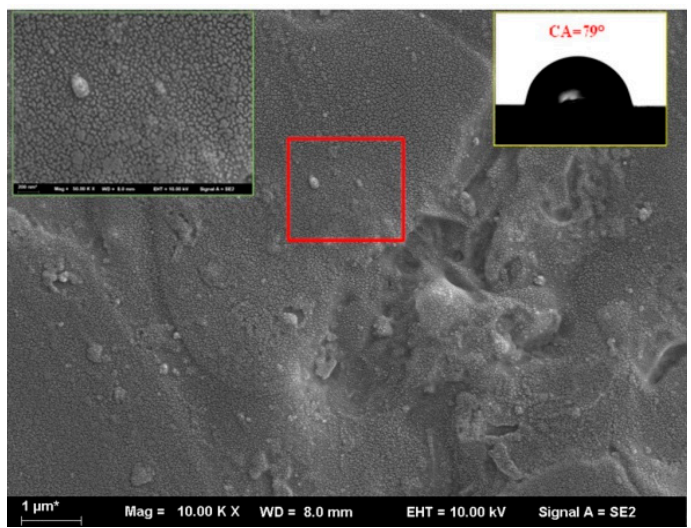

(c)

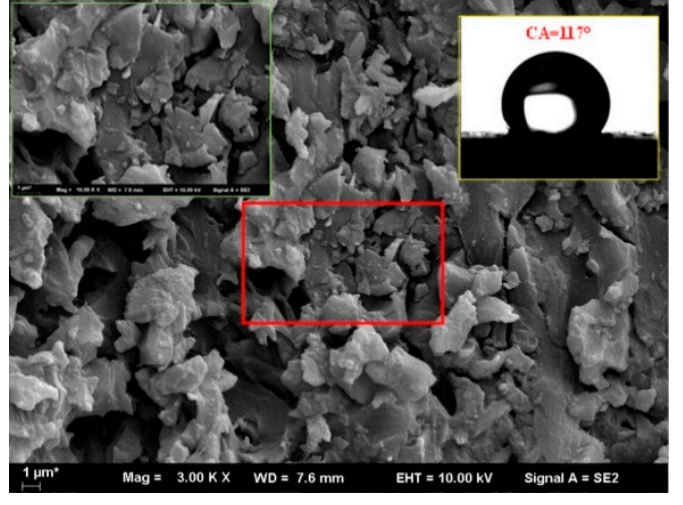

(e)

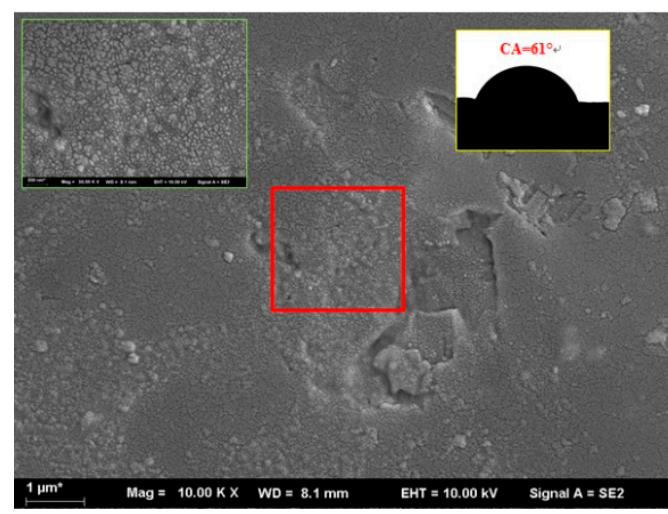

(b)

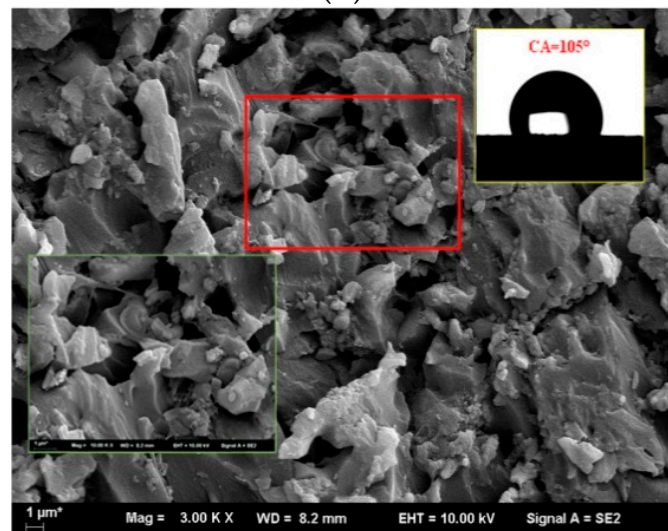

(d)

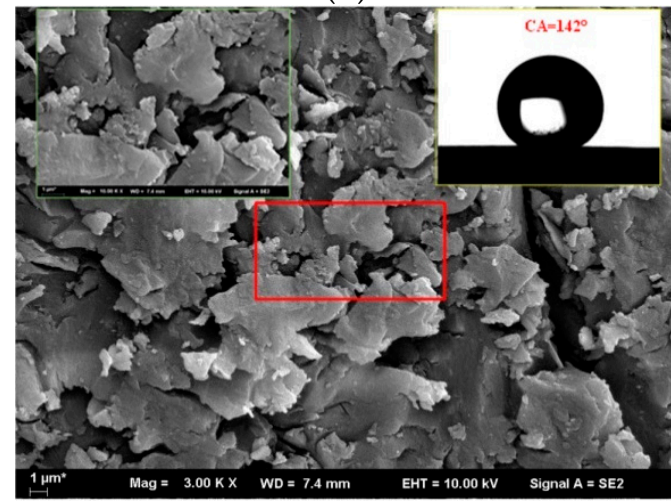

(f)

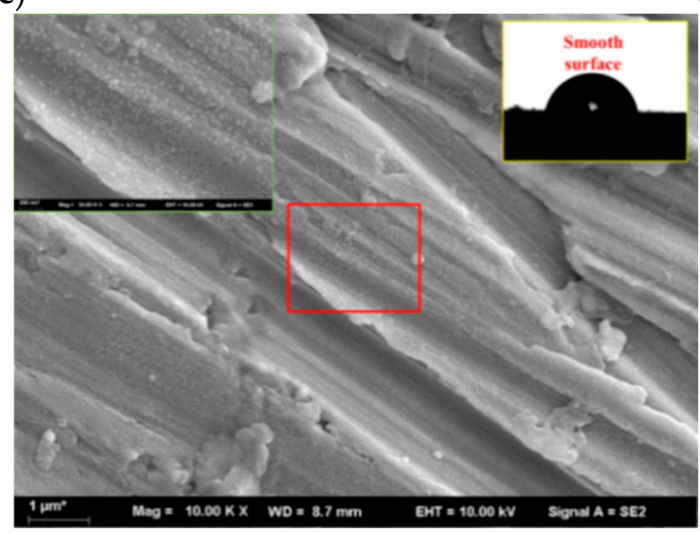

(g)

Figure 5. Scanning electron microscopy (SEM) images of: (a-f) hydrophilic and hydrophobic surfaces with contact angles (CAs) of $28^{\circ}, 61^{\circ}, 79^{\circ}, 105^{\circ}, 117^{\circ}$ and $142^{\circ}$, respectively, and (g) smooth surface (inset: $4 \mu \mathrm{L}$ of water droplet with static $\mathrm{CA}$ ). 


\section{Results}

The start-up performance is a crucial indicator of the thermosyphon operation. To enhance the overall performance of the thermosyphon, the start-up process in which the evaporator is heated to a steady state must be completed quickly and stably. In order to evaluate the influence of wettability on the start-up performance of the thermosyphon, the start-up times and two typical temperatures, i.e., the average temperatures of evaporator $T_{\text {e.ave }}$ (average of points Te1-Te3) and condenser $T_{\text {c.ave }}$ (average of points Tc1-Tc3), are selected and measured by thermocouples. In addition, all data are recorded every 5 s through a multichannel meter and saved in the computer through Monitor and Control Generated System (MCGS) software.

Figure 6 shows the start-up processes of thermosyphons from TPCT1 to TPCT7 at different input powers: $40 \mathrm{~W}, 60 \mathrm{~W}$ and $80 \mathrm{~W}$. It can be seen from the figure that $T_{\text {e.ave }}$ and $T_{\text {c.ave }}$ increase first and then maintain two different stable conditions, and all thermosyphons had a successful start-up. After the heat input power is imposed, $T_{\text {eave }}$ rapidly increases with extended heating process before the start-up is completed, implying that the working fluid is heated at the initial moment, then boiled and evaporated, after which the vapor reaches the condenser section and releases the latent heat. However, $T_{\text {c.ave }}$ does not rise at the early stage and the increase in the temperature on the condenser section is slower in the start-up process due to the heat-transfer delay. As $T_{\text {c.ave }}$ rises, the process whereby the working fluid is boiled into steam is accelerated by increasing the input power. For example, at the input powers of $40 \mathrm{~W}, 60 \mathrm{~W}$ and $80 \mathrm{~W}$, the $T_{\text {c.ave }}$ values of TPCT1-TPCT7 increase sharply at $125 \mathrm{~s}$, $70 \mathrm{~s}$ and $45 \mathrm{~s}$, respectively. The generated vapor from the evaporator section is not condensed in the condenser section due to the heat is not taken away rapidly by the external environment and that is why the temperature of the condenser keeps increasing continuously. Once the working fluid cycle is completed, the system enters a steady state.

Figure 7 shows the start-up time taken by the average evaporator temperatures of TPCT1-TPCT7 to stabilize at different input powers with different CAs on the evaporator sections. At the same input power, the TPCT with hydrophobic properties need longer start-up time than those with hydrophilic properties do at different input powers. The start-up times of the evaporator sections of TPCT4-TPCT6 with hydrophobic properties are all longer than those of TPCT1-ТРCT3 with hydrophilic properties at $40 \mathrm{~W}, 60 \mathrm{~W}$ and $80 \mathrm{~W}$. The bubbles on both hydrophilic and hydrophobic surfaces go through the entire process of bubble formation, growth, coalescence and separation which reflects the complete cycle inside the thermosyphons. The hydrophilic surface has a more complex microstructure than the hydrophobic surface as shown in Figure 5. The smaller bubble diameters are generated on the hydrophilic surface due to the rapid replenishment of fresh liquid backflow on the hydrophilic surface being faster than that of the hydrophobic surface, which further promotes the heat transfer of the thermosyphon. In contrast, the bubbles produced by the hydrophobic surface could form the gas film with the other bubbles before leaving the hydrophobic surface. Thus, the evaporator with the hydrophobic surface takes longer to start up.

The TPCT1 responds more quickly than TPCT2-TPCT7 do when the thermosyphons enter the steady state at different input powers. Thus, TPCT1 has the best start-up for thermosyphons with the same wettabilities on the evaporator and the condenser sections among TPCT1-TPCT6, while the start-up time of TPCT1 at $40 \mathrm{~W}, 60 \mathrm{~W}$ and $80 \mathrm{~W}$ is $46 \%, 50 \%$ and $55 \%$ faster than that of TPCT7 (smooth surface). The reason is that the hydrophilic surfaces have more compact structures with stronger tension forces between pore and water, which is conducive to a smaller bubble diameter speeding up the departure frequency of the bubbles [32] and promotes the heat transfer of nucleate pool boiling. Conversely, the bubbles join together to form an air blanket in a very limited time before fleeing the hydrophobic surface [33,34]. The SEM images with different CAs presented in Figure 5 indicate that the pore diameter enlarges with increasing CA. Moreover, the relationship between the CA and the pore diameter is the same as the previous research result [35]. The short knife-like nanostructure coated on the surface with CA of $28^{\circ}$ (Figure 5a) increase the heat-transfer area of phase transition and nucleation sites. Meanwhile, the nanostructure above enhances the hydrophilicity characteristics and improved 
the heat transfer of pool boiling [36], producing smaller bubbles. In consequence, the process of the heat transfer of pool boiling is significantly disturbed prompting more vapor to reach the condenser section to release more latent heat. Thus, the start-up performance of the thermosyphon is enhanced.
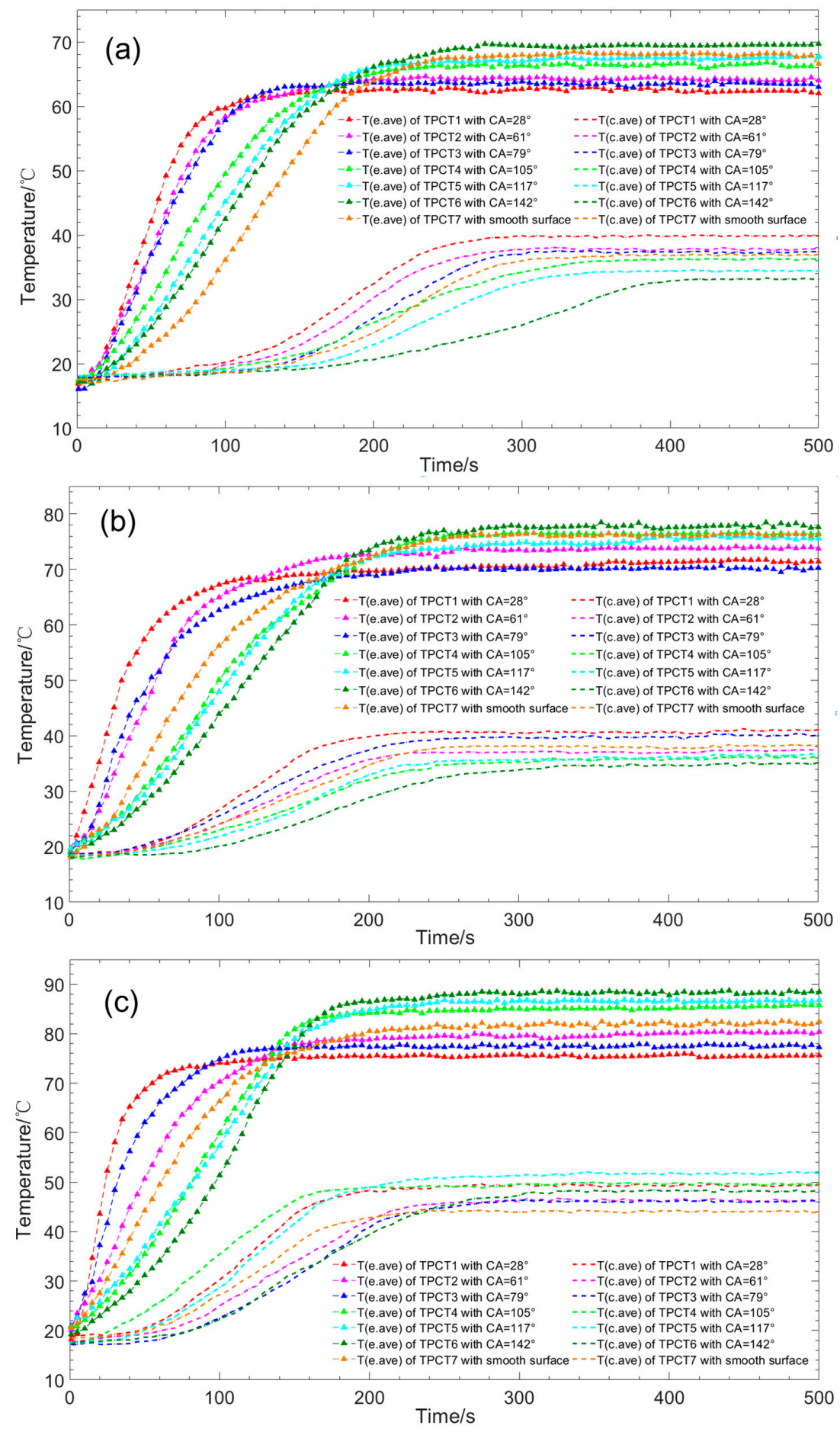

Figure 6. Start-up performances of TPCT1-TPCT7 at different input powers: (a) $Q_{i n}=40 \mathrm{~W}$; (b) $Q_{\text {in }}=$ $60 \mathrm{~W}$; (c) $Q_{\text {in }}=80 \mathrm{~W}$

Generally, the start-up time is prolonged as the CA on the evaporator sections of TPCT1-TPCT6 increase at the same input power. The time of TPCT2 is shorter than that of TPCT3 at the input power of $40 \mathrm{~W}$. However, the time of TPCT2 takes longer at the input powers of $60 \mathrm{~W}$ and $80 \mathrm{~W}$. One of the reasons is that the accuracy of CA can affect the experimental results. The CA is the average value that 
may slightly change in the process of heat transfer. The calculation results show that the CA error of samples is within $4.2 \%$, causing the start-up time of TPCT3 to be shorter than that of TPCT2. In addition, both the wettability's and the roughness of the thermosyphon surface are different, which could lead to different processes of bubble generation, growth and departure. It can be observed from Figure $5 b, c$ that the surface structure is similar, but the grooves and gaps where it is easy to generate nucleation sites density on the surface of TPCT3 are lower than TPCT2. Therefore, the sub-cooled water in the thermosyphon is in full contact with the surface of TPCT3. There are more nucleation sites on the surface of TPCT2, resulting in more bubbles. Adjacent bubbles tend to merge and form large bubbles, which are trapped on the surface of the evaporator section. Thus, the start-up speed of TPCT2 is slower. At low heat flux, the bubble number is less and could not lead to merging of a large number of bubbles. At high heat flux, the surface of TPCT2 has more bubbles that makes merging easier for bubbles. The bubble departure diameter increases and the bubble departure frequencies decrease, so the start-up time of TPCT3 is less than that of TPCT2 at the input power of $60 \mathrm{~W}$ and $80 \mathrm{~W}$.

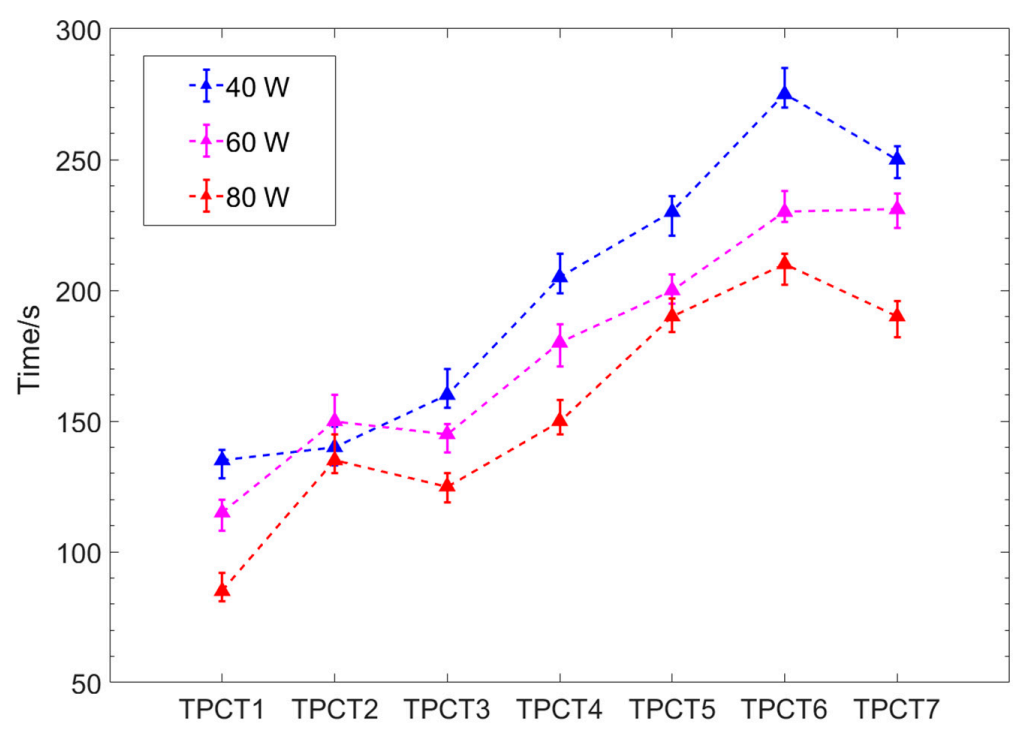

Figure 7. Times taken by the average evaporator temperatures of TPCT1-TPCT7 to stabilize at different input powers with various wettabilities on evaporator sections.

Figure 8 shows the plots of TPCTs with various wettabilities on evaporator sections versus the wall superheat degree at $40 \mathrm{~W}, 60 \mathrm{~W}$ and $80 \mathrm{~W}$. The thermosyphons with hydrophilic surfaces (CA $<90^{\circ}$ ) have not only a short start-up time, but also a low wall superheat degree. The wall superheat degree $\left(\Delta t=t_{w}-t_{s a t}, t_{w}\right.$ : wall temperature, $t_{s a t}$ : saturated temperature) of evaporator sections for thermosyphons is an important factor to quantify the characteristics of thermosyphons. Since the heat exchange mechanism of the evaporator section is pool boiling heat transfer, the most important parameter to evaluate the heat-transfer characteristics of pool boiling is the wall superheat degree. The lower wall superheat degree at the same heat power means higher heat-exchange efficiency. As a result, the wall superheat degrees $\Delta t$ of evaporator sections for TPCT1-TPCT7 were compared. The saturated pressure of each thermosyphon is $0.017212 \mathrm{MPa}$, and the corresponding saturated temperature is about $57^{\circ} \mathrm{C}$. The TPCT1 not only significantly reduces the start-up time, but also decreases the evaporator wall superheat degrees $\Delta t$ compared with those of other TPCTs at the same input power. The wall superheat degrees $\Delta t$ of TPCT 1 at $40 \mathrm{~W}, 60 \mathrm{~W}$ and $80 \mathrm{~W}$ are $55 \%, 39 \%$ and $28 \%$ lower than that of TPCT7. Similarly, it has previously been reported that the modified surfaces with different CAs influence the pool boiling in the thermosyphon [37]. In the process of boiling heat transfer, the surfaces with hydrophobic properties produce a large bubble at low heat flux [38]. There are larger and deeper pores on the hydrophobic surfaces (Figure $5 \mathrm{~d}-\mathrm{f}$ ) than those on the hydrophilic surfaces (Figure 5a-c). Thus, some air and gas film exist, which increase the thermal resistance and inhibit 
the heat transfer. Besides, the hydrophobic surface is close to the gas and then the bubble is easy to polymerize into a gas film, which prevents the liquid from replenishing to the heating wall. Therefore, the heat transfer is impeded and the boiling heat transfer performance begins to deteriorate. As a result, the superheat degrees of hydrophobic surfaces (CAs: $105^{\circ}, 117^{\circ}$ and $142^{\circ}$ ) surpass those of hydrophilic surfaces (CAs: $28^{\circ}, 61^{\circ}$ and $79^{\circ}$ ) and a smooth surface.

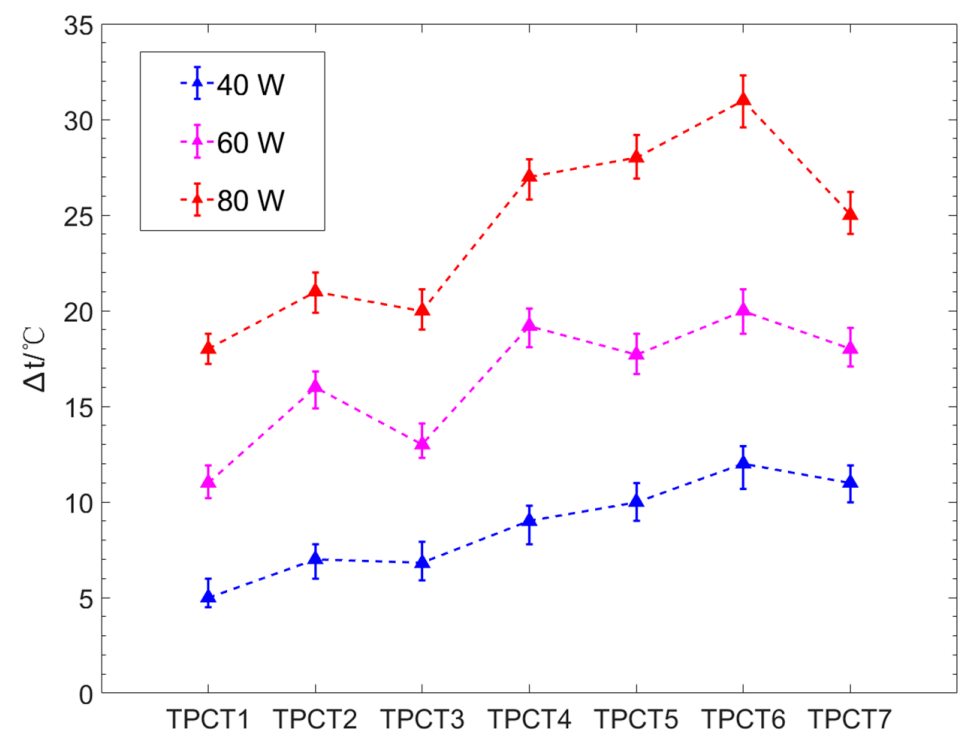

Figure 8. Relationships between wall superheat degree $\Delta t /{ }^{\circ} \mathrm{C}$ on evaporator section and different TPCTs with various wettabilities.

Furthermore, Figure 8 demonstrates that the wall superheat degree $\Delta t$ gradually increases with rising CA under the same power. As the input power increased, $\Delta t$ of the hydrophobic evaporator section rises more evidently than that of the hydrophilic evaporator section. For example, the wall superheat degree of TCPT1 increases $13^{\circ} \mathrm{C}$ from the input power of $40 \mathrm{~W}$ to $80 \mathrm{~W}$ while TCPT6 increases $19^{\circ} \mathrm{C}$. Since the hydrophobic surface produces more gas film as the power increases, the resulting large bubbles limit the heat transfer to the working fluid [39]. Thus, the superheat degree is augmented for hydrophobic surface. In contrast, the bubbles on the hydrophilic surface are smaller and quickly departs from the heating surface. Once the bubble departed, the surrounding working fluid quickly fills the remaining area and prevents the formation of large gas films with high thermal resistance. However, $\Delta t$ of the evaporator of TPCT2 is higher than that of the evaporator of TPCT3 which is consistent with the start-up time due to the inhomogeneous structures as shown in Figure $5 b$,c. This gives a higher wall superheat degree to the evaporator of TPCT2 than that of the evaporator of TPCT3.

Figure 9 illustrates the start-up processes of TPCT7-TPCT12 modified with a combination of hydrophilic and hydrophobic properties at the input powers of $40 \mathrm{~W}, 60 \mathrm{~W}$ and $80 \mathrm{~W}$. For TPCT8, TPCT9 and TPCT10 with hydrophilic inner surfaces on the evaporator sections, the start-up time is shorter than that of TPCT11 and TPCT12 with hydrophobic inner surfaces, which is consistent with the above discussion. With rising CA for TPCT7-TPCT9 on condenser sections, the start-up process on the evaporator section of TPCT8 is faster than those of TPCT9 and TPCT10. For TPCT8, the difference between the start-up time of the evaporator and the time reaching the stable state of the condenser is gradually decreased from $200 \mathrm{~s}$ to $150 \mathrm{~s}$ with the increase from $40 \mathrm{~W}$ to $80 \mathrm{~W}$, which enhances the evaporator-condenser phenomenon induced by combined hydrophilic and hydrophilic properties. The addition of a hydrophilic surface to the surface of the evaporator section can quickly induce the sub-cooled water after the formation of bubbles, which can quickly take away the heat of the surface of the evaporator section. Thus, the stable temperature reduces. The addition of a hydrophobic surface on the surface of the condenser section rapidly reduces the water droplets in the condenser section, which indirectly speeds up the recycle of working fluid inside the thermosyphon. As the input power 
increased, TPCT8 and TPCT9 both have almost the same start-up times of $180 \mathrm{~s}$ and $200 \mathrm{~s}$ at input power of $60 \mathrm{~W}$ and $80 \mathrm{~W}$, respectively. However, TPCT8 has a higher average temperature of $2{ }^{\circ} \mathrm{C}$ on the evaporator than that of TPCT9. Furthermore, the average temperature on the condenser section of TPCT9 $\left(\mathrm{CA}: 117^{\circ}\right)$ gradually approaches that on the condenser section of TPCT8 (CA: $\left.105^{\circ} \mathrm{C}\right)$ with increasing input power at an average temperature of $54{ }^{\circ} \mathrm{C}$.
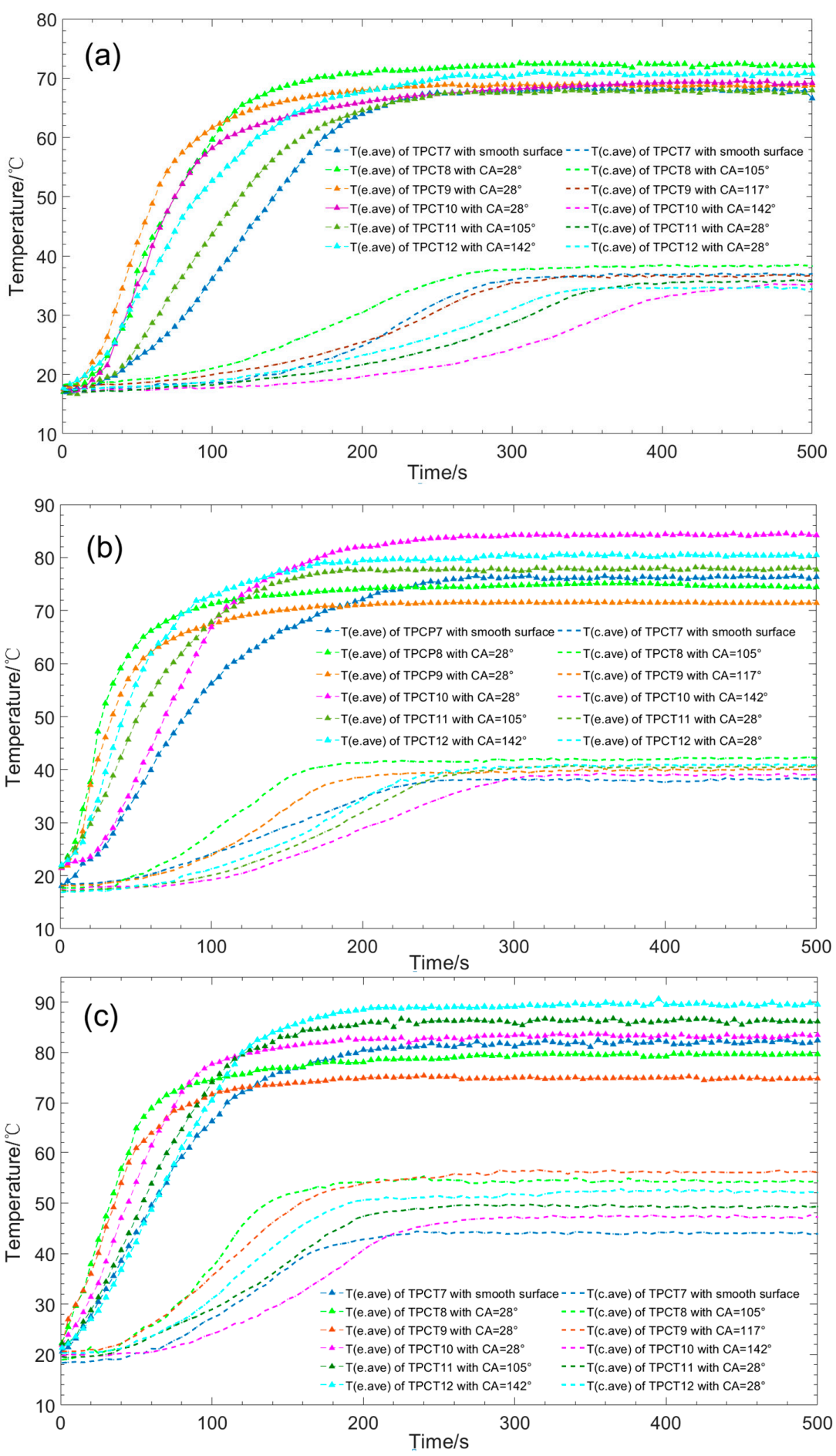

Figure 9. Start-up performances of TPCT7 (smooth surface) and TPCT8-TPCT12 with combined hydrophilic and hydrophobic properties at different heat input powers: (a) $Q_{\text {in }}=40 \mathrm{~W}$;(b) $Q_{\text {in }}=60 \mathrm{~W}$; (c) $Q_{\text {in }}=80 \mathrm{~W}$. 
For TPCT11 and TPCT12 with hydrophilic inner surfaces on the condenser sections (both with CA $28^{\circ}$ ), the condenser sections require shorter times to stabilize than that of TPCT7 with a smooth surface with increasing input power. Although the evaporator sections are hydrophobically modified, the steam still sufficiently releases heat on the inner surface of hydrophilically modified condenser sections, and the condensate fully contacts with the hydrophilic surface to release latent and sensible heats. Furthermore, it is found that the temperature difference between the evaporator $\left(\mathrm{CA}: 28^{\circ}\right)$ and condenser (CA: $105^{\circ} \mathrm{C}$ ) of TPCT8 gradually decreases with increase in the input power, thus surpassing those of TPCT9-TPCT12 concerning isothermal properties. As a result, TPCT8 has the best start-up characteristics among TPCT8-TPCT12 under the same input power. It is postulated that the interaction between the liquid drops and the wall is attenuated with an increase in the CA, and the condensate falls down more easily as smaller drops and fast reflux to the evaporator section, which may suppress the release of latent and sensible heats in the condenser.

\section{Conclusions}

In this study, the influence of wettability properties inside the inner surface of thermosyphons on the start-up characteristics is fully investigated under different input powers. Chemical techniques are performed to fabricate the surfaces with different wettabilities that is quantified in the form of the CA inside the evaporator and the condenser sections. The experimental results demonstrate that different CAs not only significantly affect the start-up time but also influence the temperature variations and distributions of the outer walls of the evaporator and the condenser sections. Detailed conclusions can be drawn as follows:

(1) For thermosyphons with the same wettabilities on the evaporator and the condenser sections among TPCT1-TPCT6, the introduction of hydrophilic properties inside the evaporator section not only significantly shortens the start-up time but also decreases the start-up temperature. At the same input power, the start-up time of a thermosyphon with $\mathrm{CA}<90^{\circ}$ is shorter than that with CA $>90^{\circ}$. The start-up time of TPCT with CA $=28^{\circ}$ has the shortest start-up time, while under the input powers of $40 \mathrm{~W}, 60 \mathrm{~W}$ and $80 \mathrm{~W}$ it is $46 \%, 50 \%$ and $55 \%$ shorter than that of TPCT with a smooth surface, respectively. The start-up time becomes longer with the increase of CA of the evaporator sections.

(2) As the CAs on the evaporator sections of TPCT1-TPCT6 increase, the wall superheat degree gradually increases. The TPCT with CA $=28^{\circ}$ has a minimum superheat degree at input powers of $40 \mathrm{~W}, 60 \mathrm{~W}$ and $80 \mathrm{~W}$, and the wall superheat degree is $55 \%, 39 \%$ and $28 \%$ lower than that of TPCT with smooth surfaces, respectively. In addition, the superheat degree of the hydrophobic evaporator section increases more obviously than that of the hydrophilic with increasing input power. In the experiment, the TPCT with $\mathrm{CA}=142^{\circ}$ has the highest superheat degree among TPCT1-TPCT6.

(3) For thermosyphons with combined hydrophilic and hydrophobic properties, the start-up time of the evaporator section with $\mathrm{CA}<90^{\circ}$ and the condenser section with $\mathrm{CA}>90^{\circ}$ is less than the evaporator section with $\mathrm{CA}>90^{\circ}$ and the condenser section with $\mathrm{CA}<90^{\circ}$. With the increase of CA on the condenser sections of TPCT8-TPCT10, the start-up process of TPCT8 is faster than those of TPCT9 and TPCT10 with the same $\mathrm{CA}=28^{\circ}$ on the evaporator section. The experimental results and data analysis demonstrate that the start-up time of the TPCT8 with CA $=28^{\circ}$ on the evaporator section and $\mathrm{CA}=105^{\circ}$ on the condenser section is the shortest among TPCT7-TPCT12.

(4) In this paper, the surfaces with CAs of $28^{\circ}, 61^{\circ}, 79^{\circ}, 105^{\circ}, 117^{\circ}$ and $142^{\circ}$ are fabricated inside the evaporator and the condenser sections of the thermosyphons. The experimental results show that the ТРCT with $\mathrm{CA}=28^{\circ}$ on both the evaporator and the condenser section has the best start-up characteristics considering start-up time and wall superheat degree, which reflect the optimal wettabilitiy inside the inner surface of thermosyphons for industrial reference. Further research directions should extend to the preparation and investigation of superhydrophobic and superhydrophilic surfaces in the analysis of the thermal performance and start-up characteristics. 
Author Contributions: Project administration, supervision, writing-review and editing, Z.Z.; methodology and writing-original draft preparation, X.M. and P.J.; investigation, data curation, formal analysis and validation, X.M., P.J., S.Y., S.L. and X.C. All authors have read and agreed to the published version of the manuscript.

Funding: The authors gratefully acknowledge that this work was supported by Jiangsu marine and fishery science and technology innovation and extension project (HY2017-8) and Zhenjiang funds for the key research and development project (GY2016002-1).

Conflicts of Interest: The authors declare no conflict of interest.

\title{
Nomenclature
}

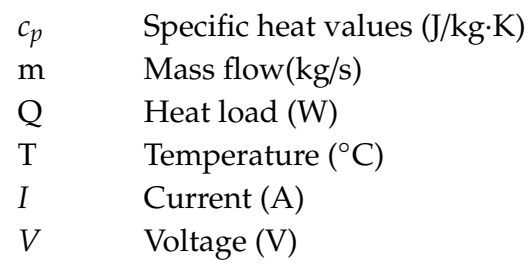

\section{Greek symbols}

$$
\begin{array}{ll}
\Delta t & \text { Wall superheat degree }\left({ }^{\circ} \mathrm{C}\right) \\
\eta & \text { Efficiency of the thermosyphon }
\end{array}
$$

\section{Subscripts}

$\begin{array}{ll}\text { a } & \text { Adiabatic section } \\ \text { ave } & \text { Average } \\ \text { c } & \text { Condenser section } \\ \text { e } & \text { Evaporator section } \\ \text { in } & \text { Cooling water inlet/ Input power } \\ \text { out } & \text { Cooling water outlet } \\ \text { sat } & \text { Saturated } \\ \text { w } & \text { Wall/water }\end{array}$

\section{Acronyms}

\author{
CA Contact angle \\ MCGS Monitor and Control Generated System \\ SEM Scanning electron microscopy \\ TPCP Two-phase closed thermosyphon
}

\section{References}

1. Chang, Y.; Cheng, C.; Wang, J.; Chen, S. Heat pipe for cooling of electronic equipment. Energy Convers. Manag. 2008, 49, 3398-3404. [CrossRef]

2. Jafari, D.; Franco, A.; Filippeschi, S.; Di Marco, P. Two-phase closed thermosyphons: A review of studies and solar applications. Renew. Sustain. Energy Rev. 2016, 53, 575-593. [CrossRef]

3. Ziapour, B.M.; Khalili, M.B. PVT type of the two-phase loop mini tube thermosyphon solar water heater. Energy Convers. Manag. 2016, 129, 54-61. [CrossRef]

4. Jouhara, H.; Merchant, H. Experimental investigation of a thermosyphon based heat exchanger used in energy efficient air handling units. Energy 2012, 39, 82-89. [CrossRef]

5. Gaugler, R.S. Heat Transfer Device. U.S. Patent 2,350,348, 6 June 1994.

6. Faghri, A. Heat Pipe Science and Technology; Taylor \& Francis: Philadelphia, PA, USA, 1995.

7. Shabgard, H.; Allen, M.J.; Sharifi, N.; Benn, S.P.; Faghri, A.; Bergman, T.L. Heat pipe heat exchangers and heat sinks: Opportunities, challenges, applications, analysis, and state of the art. Int. J. Heat Mass Transf. 2015, 89, 138-158. [CrossRef] 
8. Amatachaya, P.; Srimuang, W. Comparative heat transfer characteristics of a flat two-phase closed thermosyphon (FTPCT) and a conventional two-phase closed thermosyphon (CTPCT). Int. Commun. Heat Mass Transfer. 2010, 37, 293-298. [CrossRef]

9. Zhao, Z.; Jiang, P.; Zhou, Y.; Zhang, Y.; Zhang, Y. Heat transfer characteristics of two-phase closed thermosyphons modified with inner surfaces of various wettabilities. Int. Commun. Heat Mass Transfer. 2019, 103, 100-109. [CrossRef]

10. Lataoui, Z.; Jemni, A. Experimental investigation of a stainless steel two-phase closed thermosyphon. Appl. Therm. Eng. 2017, 121, 721-727. [CrossRef]

11. Moradikazerouni, A.; Afrand, M.; Alsarraf, J.; Mahian, O.; Wongwises, S.; Tran, M.-D. Comparison of the effect of five different entrance channel shapes of a micro-channel heat sink in forced convection with application to cooling a supercomputer circuit board. Appl. Therm. Eng. 2019, 150, 1078-1089. [CrossRef]

12. Moradikazerouni, A.; Afrand, M.; Alsarraf, J.; Wongwises, S.; Asadi, A.; Nguyen, T.K. Investigation of a computer CPU heat sink under laminar forced convection using a structural stability method. Int. J. Heat Mass Transf. 2019, 134, 1218-1226. [CrossRef]

13. Rahimi, M.; Asgary, K.; Jesri, S. Thermal characteristics of a resurfaced condenser and evaporator closed two-phase thermosyphon. Int. Commun. Heat Mass Transf. 2010, 37, 703-710. [CrossRef]

14. Singh, R.R.; Selladurai, V.; Ponkarthik, P.; Solomon, A.B. Effect of anodization on the heat transfer performance of flat thermosyphon. Exp. Therm. Fluid Sci. 2015, 68, 574-581. [CrossRef]

15. Solomon, A.B.; Daniel, V.A.; Ramachandran, K.; Pillai, B.; Singh, R.R.; Sharifpur, M.; Meyer, J. Performance enhancement of a two-phase closed thermosiphon with a thin porous copper coating. Int. Commun. Heat Mass Transf. 2017, 82, 9-19. [CrossRef]

16. Solomon, A.B.; Mathew, A.; Ramachandran, K.; Pillai, B.; Karthikeyan, V. Thermal performance of anodized two phase closed thermosyphon (TPCT). Exp. Therm. Fluid Sci. 2013, 48, 49-57. [CrossRef]

17. Noie, S. Heat transfer characteristics of a two-phase closed thermosyphon. Appl. Therm. Eng. 2005, 25, 495-506. [CrossRef]

18. Gedik, E. Experimental investigation of the thermal performance of a two-phase closed thermosyphon at different operating conditions. Energy Build. 2016, 127, 1096-1107. [CrossRef]

19. Ma, Y.; Shahsavar, A.; Moradi, I.; Rostami, S.; Moradikazerouni, A.; Yarmand, H.; Zulkifli, N.W.B.M. Using finite volume method for simulating the natural convective heat transfer of nano-fluid flow inside an inclined enclosure with conductive walls in the presence of a constant temperature heat source. Phys. A Stat. Mech. Appl. 2019, 123035. [CrossRef]

20. Vo, D.D.; Alsarraf, J.; Moradikazerouni, A.; Afrand, M.; Salehipour, H.; Qi, C. Numerical investigation of $\gamma$-AlOOH nano-fluid convection performance in a wavy channel considering various shapes of nanoadditives. Powder Technol. 2019, 345, 649-657. [CrossRef]

21. Sun, Q.; Qu, J.; Yuan, J.; Wang, H. Start-up characteristics of MEMS-based micro oscillating heat pipe with and without bubble nucleation. Int. J. Heat Mass Transf. 2018, 122, 515-528. [CrossRef]

22. Guo, Q.; Guo, H.; Yan, X.; Wang, X.; Ye, F.; Ma, C. Experimental study of start-up performance of sodium-potassium heat pipe. J. Eng. Thermophys. 2014, 35, 2508-2512.

23. Guo, Q.; Guo, H.; Yan, X.; Wang, X.; Ye, F.; Ma, C. Effect of the evaporator length on start-up performance fo sodium-potassium alloy heat pipe. J. Eng. Thermophys. 2016, 37, 1717-1720.

24. Wang, X.; Xin, G.; Tian, F.; Cheng, L. Start-up behavior of gravity heat pipe with small diameter. CIESC J. 2012, 63, 94-98.

25. Huang, J.; Wang, L.; Shen, J.; Liu, C. Effect of non-condensable gas on the start-up of a gravity loop thermosyphon with gas-liquid separator. Exp. Therm. Fluid Sci. 2016, 72, 161-170. [CrossRef]

26. Joung, W.; Yu, T.; Lee, J. Experimental study on the loop heat pipe with a planar bifacial wick structure. Int. J. Heat Mass Transf. 2008, 51, 1573-1581. [CrossRef]

27. Singh, R.; Akbarzadeh, A.; Mochizuki, M. Operational characteristics of a miniature loop heat pipe with flat evaporator. Int. J. Therm. Sci. 2008, 47, 1504-1515. [CrossRef]

28. Ji, X.; Wang, Y.; Xu, J.; Huang, Y. Experimental study of heat transfer and start-up of loop heat pipe with multiscale porous wicks. Appl. Therm. Eng. 2017, 117, 782-798. [CrossRef]

29. Huang, B.; Huang, H.; Liang, T. System dynamics model and startup behavior of loop heat pipe. Appl. Therm. Eng. 2009, 29, 2999-3005. [CrossRef] 
30. Dai, C.; Yang, L.; Xie, J.; Wang, T. Nutrient diffusion control of fertilizer granules coated with a gradient hydrophobic film. Colloids Surf. A Physicochem. Eng. Asp. 2020, 588, 124361. [CrossRef]

31. Anosov, A.; Smirnova, E.Y.; Sharakshane, A.; Nikolayeva, E.; Zhdankina, Y.S. Increase in the current variance in bilayer lipid membranes near phase transition as a result of the occurrence of hydrophobic defects. Biochim. Biophys. Acta (BBA)-Biomembr. 2020, 1862, 183147. [CrossRef]

32. Li, Y.; Liu, Z.; Wang, G. A predictive model of nucleate pool boiling on heated hydrophilic surfaces. Int. J. Heat Mass Transfer. 2013, 65, 789-797. [CrossRef]

33. Phan, H.T.; Caney, N.; Marty, P.; Colasson, S.; Gavillet, J. Surface wettability control by nanocoating: The effects on pool boiling heat transfer and nucleation mechanism. Int. J. Heat Mass Transfer. 2009, 52, 5459-5471. [CrossRef]

34. Hsu, C.; Chen, P. Surface wettability effects on critical heat flux of boiling heat transfer using nanopartical coatings. Int. J. Heat Mass Transfer. 2012, 55, 3713-3719. [CrossRef]

35. Leese, H.; Bhurtun, V.; Lee, K.P.; Mattia, D. Wetting behavior of hydrophilic and hydrophobic nanostructured porous anodic alumina. Colloids Surf. A Physicochem. Eng. Asp. 2013, 420, 53-58. [CrossRef]

36. Shi, B.; Wang, Y.; Chen, K. Pool boiling heat transfer enhancement with copper nanowire arrays. Appl. Therm. Eng. 2015, 75, 115-121. [CrossRef]

37. Bankoff, S. Ebullition from solid surfaces in the absence of a pre-existing gaseous phase. Trans. Am. Mech. Eng. 1957, 79, 735-740.

38. Zheng, X.; Ji, X.; Wang, Y.; Xu, J. Study of the pool boiling heat transfer on the superhydrophilic and Superhydrophobic surface. Prog. Chem. Ind. 2016, 12, 3793-3798.

39. Thiagarajan, S.J.; Yang, R.; King, C.; Narumanchi, S. Bubble dynamics and nucleate pool boiling heat transfer on microporous copper surfaces. Int. J. Heat Mass Transfer 2015, 89, 1297-1315. [CrossRef]

(C) 2020 by the authors. Licensee MDPI, Basel, Switzerland. This article is an open access article distributed under the terms and conditions of the Creative Commons Attribution (CC BY) license (http://creativecommons.org/licenses/by/4.0/). 